\title{
Efeitos de diferentes relações dietéticas de energia metabolizável: proteína bruta e do peso inicial de pintos sobre o desempenho e o rendimento de carcaça em frangos de corte fêmeas
}

\author{
Rafael Azevedo \\ MURAROLLI ${ }^{1}$ \\ Ricardo de \\ ALBURQUEQUE ${ }^{1}$ \\ Estela KOBASHIGAWA ${ }^{1}$ \\ Vinicius Diogo Azevedo \\ MURAROLLI ${ }^{1}$ \\ Messias Alves de TRINDADE \\ NETO $^{1}$ \\ Lúcio Francelino de \\ ARAÚJO
}

\section{Correspondência para:}

Rafael Azevedo Murarrolli, Av. Duque de Caxias - norte, 225 Pirassununga SP CEP: 13.635-900 e-mail: rafamura@usp.br

Recebido para publicação: 30/03/2007 Aprovado para publicação: 30/10/2008

\author{
1 - Departamento de Nutrição e Produção Animal da Faculdade de Medicina \\ Veterinária e Zootecnia da Universidade de São Paulo, Pirassununga-SP \\ 2 - Faculdade de Zootecnia e Engenharia de Alimentos da Universidade de São \\ Paulo, Pirassununga-SP
}

\begin{abstract}
Resumo
O estudo foi realizado para verificar o efeito de diferentes relações dietéticas de energia metabolizável:proteína bruta e do peso inicial de pintos de corte de 01 sobre o desempenho e rendimento de carcaça em frangos de corte. Foram utilizados 640 pintos, fêmeas, de uma linhagem comercial para corte (Cobb). O delineamento experimental utilizado foi de blocos ao acaso, em esquema fatorial $2 \times 2$, sendo empregados dois níveis de peso de pintos de 01 dia (38g e 46g) e dois níveis de relação EM:PB (Alto - 149,8; 174,4 e; 194,4 e, Baixo - 130,0; 150,0 e; 166,7, para ração inicial, crescimento e final, respectivamente) totalizando, assim, 4 tratamentos, cada um com 4 repetições de 40 aves, criados até 48 dias de idade. Foram avaliados o Consumo de Ração (CR), Ganho de Peso (GP), Conversão Alimentar (CA) durante o período experimental e, Rendimento de Carcaça e Rendimento de Cortes (Asa, coxa+sobrecoxa, peito, cabeça, pé e dorso) no final do período experimental. Nas variáveis CR e GP não foram observados efeitos significativos $(\mathrm{P}>0,05)$ em nenhum dos tratamentos e períodos. Na variável $\mathrm{CA}$, observou-se efeito significativo $(\mathrm{P}<0,05)$ no período de 1 a 35 dias de idade onde as aves alimentadas com a dieta com Relação EM:PB baixa apresentaram uma pior conversão alimentar, independente do peso inicial. No rendimento de carcaça houve efeito significativo $(\mathrm{P}<0,05)$, onde as aves com maior peso inicial obtiveram uma melhor porcentagem de rendimento quando receberam, durante todo o período de criação, dietas com relação EM:PB alta.
\end{abstract}

\section{Introdução}

Existem diferentes exigências nutricionais e consequente crescimento das fêmeas em relação aos machos. Existe uma tendência na criação de lotes sexados, objetivando o fornecimento de rações adequadas para a obtenção de melhor uniformidade no processo de abate. As vantagens no ajuste de equipamentos da planta de processamento são possíveis quando as aves são criadas separadamente já que a variação nos pesos corporais é

\author{
Palavras-chave: \\ Frango de corte. \\ Peso inicial. \\ Proteína bruta. \\ Energia metabolizável. \\ Desempenho.
}

menor que em grupos de lotes mistos. A criação de somente frangos de corte fêmeas pode trazer vantagens, tais como as fêmeas podem ser criadas em maior densidade por metro quadrado e no abatedouro, as carcaças apresentam-se mais uniforme permitindo ajustar o equipamento para a obtenção de um processamento mais eficiente. ${ }^{1,2}$

Os requerimentos nutricionais têm como base as necessidades dos frangos de corte em termos de manutenção e produção. $^{3}$ As necessidades de produção dependem do potencial genético e do sexo. 
Tavares $^{4}$ encontrou diferença significativa $(\mathrm{P}<0,05)$ entre sexos para o rendimento de sobrecoxas, onde as fêmeas apresentaram maior rendimento. Holsheimer e Veercamp ${ }^{5}$ estudaram o efeito de altos níveis energéticos nas dietas de machos e fêmeas e não encontraram diferenças significativas $(\mathrm{P}>0,05)$ para peito e coxa. Ao contrário, Mendes et al. ${ }^{6}$ encontraram maior rendimento de coxas para machos e de peito para fêmeas. O objetivo do presente trabalho é o de obter maiores esclarecimentos sobre o efeito da utilização de dietas com diferentes relações energia metabolizável:proteína bruta para pintos de corte fêmeas com diferentes pesos iniciais sobre o desempenho, rendimento de carcaça e vísceras comestíveis.

\section{Material e Método}

O experimento foi conduzido no aviário experimental do Departamento de Nutrição e Produção Animal da Faculdade de Medicina Veterinária e Zootecnia da Universidade de São Paulo, Campus de Pirassununga, estado de São Paulo, no período de março a maio de 2006, totalizando 48 dias de criação.

Foram utilizados 640 pintos, fêmeas, de linhagem comercial especializada para corte (Cobb), criados em galpão de alvenaria dividido em boxes, de $4,25 \mathrm{~m}^{2}$ cada, sendo a criação dos animais em piso. $\mathrm{O}$ delineamento experimental utilizado foi de blocos ao acaso, em esquema fatorial $2 \times 2$, sendo empregados dois níveis de peso de pintos de 01 dia (38 e 46g) e dois níveis de relação EM:PB (Alto - 149,8; 174,4 e 194,4 e Baixo - 130,0; 150,0 e 166,7, para ração inicial, crescimento e final, respectivamente) totalizando assim 4 tratamentos, cada um com 4 repetições de 40 aves. Os resultados foram analisados através do programa computacional Statistical Analysis System $(\mathrm{SAS})^{7}$, sendo anteriormente verificada a normalidade dos resíduos pelo Teste de Shapiro-Wilk (PROC UNIVARIATE) e as variâncias comparadas pelo Teste de Hartley. Os dados (variável dependente) que não atenderam a estas premissas foram submetidos à transformação logarítmica $[\log (\mathrm{X}+1)]$ ou pela raiz quadrada $[R Q(X+1 / 2)]$. Os dados originais ou transformados, quando este último procedimento foi necessário, foram submetidos à análise de variância que separou como causas de variação efeito de tratamento e efeito de blocos. Os blocos foram formados em função da localização dos boxes no galpão. Os efeitos de tratamento foram separados através do teste de Tukey. Tal análise foi realizada utilizando-se procedimento General Linear Model (PROC GLM do SAS).

As análises referentes aos parâmetros zootécnicos foram efetuadas conforme descrito anteriormente, porém adicionadas do fator medidas repetidas no tempo, referentes às semanas de colheita dos dados. As probabilidades das interações com o tempo foram determinadas pelo teste de Greenhouse-Geisse, utilizando-se o comando REPEATED gerado pelo procedimento GLM (PROC GLM do SAS). Análises por tempo somente foram realizadas quando as interações entre tempo e tratamentos foram significativas. Para tal foi utilizado o comando SLICE do GLM do SAS. Foi utilizado o nível de significância de $5 \%$ para todos os testes realizados.

As variáveis de desempenho (consumo de ração, ganho de peso, conversão alimentar e mortalidade) foram mensuradas semanalmente durante todo o período de criação e, aos 48 dias de idade, foram selecionadas e abatidas 8 aves de cada tratamento, variando aproximadamente 5\% do peso vivo médio da parcela, para estudo do rendimento da carcaça, com particular avaliação da porcentagem de gordura abdominal e víceras comestíveis, sendo considerada em relação ao peso da carcaça limpa.

As rações foram elaboradas a base de milho e soja, sendo isoprotéicas (Tabela 1). A alimentação foi dividida em três etapas: inicial (1 a 21 dias), crescimento (22 a 35 dias) e final (36 a 48 dias). Estas foram formuladas de acordo com os níveis nutricionais descritos por Rostagno, Albino 
Tabela 1 - Composição percentual, valor nutricional estimado e relações E:PB das rações experimentais nas diferentes fases de criação

\begin{tabular}{|c|c|c|c|c|c|c|}
\hline \multirow[t]{2}{*}{ Ingredientes } & \multicolumn{3}{|c|}{ Dietas (Relação EM:PB Alta) $^{1}$} & \multicolumn{3}{|c|}{ Dietas (Relação EM:PB Baía) $^{1}$} \\
\hline & $\begin{array}{l}\text { Inicial } \\
(149,8)\end{array}$ & $\begin{array}{c}\text { Crescimento } \\
(174,4)\end{array}$ & $\begin{array}{c}\text { Final } \\
(194,4)\end{array}$ & $\begin{array}{l}\text { Inicial } \\
(130,0)\end{array}$ & $\begin{array}{l}\text { Crescimento } \\
(150,0)\end{array}$ & $\begin{array}{c}\text { Final } \\
(166,7)\end{array}$ \\
\hline Milho Moído 8,3\% & 52,944 & 56,302 & 59,613 & 52,611 & 63,908 & 67,744 \\
\hline Trigo, Farelo & - & - & - & 5,0 & - & - \\
\hline Soja, Farelo $45 / 80$ & 37,403 & 31,885 & 27,768 & 35,664 & 30,446 & 26,226 \\
\hline $\mathrm{Sal}$ & 0,5 & 0,5 & 0,5 & 0,5 & 0,5 & 0,5 \\
\hline Inerte & - & - & - & 1,404 & 1,400 & 1,400 \\
\hline Fosfato Bicálcico & 1,902 & 1,694 & 1,577 & 1,836 & 1,693 & 1,574 \\
\hline Oleo Soja & 5,334 & 7,825 & 8,751 & 1,000 & 0,233 & 0,712 \\
\hline Calcário Calcítico & 1,040 & 0,934 & 0,870 & 1,072 & 0,938 & 0,874 \\
\hline Premix Vitamínico-Mineral ${ }^{2}$ & 0,3 & 0,3 & 0,3 & 0,3 & 0,3 & 0,3 \\
\hline L-Lisina & 0,180 & 0,200 & 0,262 & 0,208 & 0,227 & 0,291 \\
\hline L-Treonina & 0,085 & 0,083 & 0,107 & 0,094 & 0,087 & 0,111 \\
\hline DL-Metionina & 0,287 & 0,252 & 0,252 & 0,286 & 0,243 & 0,243 \\
\hline Antioxidante & 0,025 & 0,025 & - & 0,025 & 0,025 & 0,025 \\
\hline TOTAL & 100,0 & 100,0 & 100,0 & 100,0 & 100,0 & 100,0 \\
\hline \multicolumn{7}{|l|}{ COMPOSIĊÃO CALCULADA } \\
\hline Proteina Bruta (\%) & 21,7 & 19,5 & 18,0 & 21,7 & 19,5 & 18,0 \\
\hline Cálcio $(\%)$ & 0,94 & 0,84 & 0,78 & 0,94 & 0,84 & 0,78 \\
\hline Fósforo Total (\%) & 0,7275 & 0,6659 & 0,6287 & 0,7534 & 0,6783 & 0,6420 \\
\hline P disponível (\%) & 0,47 & 0,42 & 0,39 & 0,47 & 0,42 & 0,39 \\
\hline Energia Metabolizável (kcal/kg) & 3.250 & 3.400 & 3.500 & 2.820 & 2.925 & 3.000 \\
\hline LIS Digestivel (\%) & 1,22 & 1,10 & 1,05 & 1,22 & 1,10 & 1,05 \\
\hline M+C Digestivel (\%) & 0,8662 & 0,7810 & 0,7455 & 0,8662 & 0,7810 & 0,7455 \\
\hline Treonina Digestivel (\%) & 0,7930 & 0,7150 & 0,6825 & 0,7930 & 0,7150 & 0,6825 \\
\hline Triptofano Digestivel & 0,2366 & 0,2069 & 0,1850 & 0,2355 & 0,2021 & 0,1799 \\
\hline Sódio (Total) (\%) & 0,2241 & 0,2231 & 0,2226 & 0,2234 & 0,2250 & 0,2246 \\
\hline
\end{tabular}

1 - Valores expressos em porcentagem; 2 - Fomecido por kg da dieta: Vitamina A 1.762.500,00 U.I.; Vitamina D3 425.625,00 U.I.; Vitamina E 2.486,400 mg; Vitamina K3 300,000 mg; Vitamina B1 335,000 mg; Vitamina B2 750,000 mg; Vitamina B6 415,000 mg; Vitamina B12 2.000,000 meg; Acido Nicotinico $5.000,000 \mathrm{mg}$ Pant. de Cálcio 2.000,000 mg; Acido Fólico 125,775 mg; Biotina 16,770 mg; Metionima 266,657 g; Cloreto de Colina 49,800 g; Sulfato de Colostima $336,000 \mathrm{mg}$;
Bacitracina de zinco $1.702,500 \mathrm{mg}$; Narazim 6,667 g; Nicarbazina 6,667 g; Lisina 49,000 g; Ferro 7.238,809 mg; Manganês 9.330,020 mg; Zimco 7.238,809 mg; Cobre 1.439,719 mg; Selênio $56,302 \mathrm{mg}$ e; Iodo $93,635 \mathrm{mg}$

e Donzele ${ }^{8}$, variando o nível de energia, consequentemente, variando a relação EM:PB.

\section{Resultados e Discussão}

Os dados referentes a Consumo de Ração e Ganho de Peso estão apresentados nas tabelas 2 e 3 , respectivamente. Para estas variáveis não foram observados efeitos significativos $(\mathrm{P}>0,05)$ em nenhum dos tratamentos e períodos.

Sakomura et al. ${ }^{9}$, estudando o efeito do nível de energia metabolizável da dieta no desempenho e metabolismo de frangos de corte, corroboram com os resultados deste trabalho onde o nível de energia da ração não proporcionou efeito sobre o consumo de ração. Sabino et al. ${ }^{10}$, testando níveis protéicos na ração de frango de corte na fase de crescimento, obtiveram resultados semelhantes ao presente trabalho, não

Tabela 2 - Consumo de ração médio dos frangos durante o período experimental - Pirassununga - 2007

\begin{tabular}{clccc}
\hline \multirow{2}{*}{ Peso inicial } & & \multicolumn{3}{c}{ Dias } \\
\cline { 3 - 5 } & & $\begin{array}{c}\mathbf{1 - 2 1} \\
(\mathbf{k g})\end{array}$ & $\begin{array}{c}\mathbf{1 - 3 5} \\
(\mathbf{k g})\end{array}$ & $\begin{array}{c}\mathbf{1 - 4 8} \\
(\mathbf{k g})\end{array}$ \\
\hline Pesada & Rel EM:PB alta & 0,906 & 2,517 & 4,559 \\
& Rel EM:PB & 1,004 & 2,808 & 5,041 \\
& baixa & & & \\
\hline Leve & Rel EM:PB alta & 0,841 & 2,333 & 4,359 \\
& Rel EM:PB & 0,981 & 2,735 & 4,947 \\
& baixa & & & \\
\hline Probabilidades & CV (\%) & 7,70 & 8,06 & 6,37 \\
\hline & Rel EM:PB & $<, 0001$ & $<, 0001$ & $<, 0001$ \\
& Peso Inicial & 0,0164 & 0,0151 & 0,0108 \\
& Interação & 0,2211 & 0,2499 & 0,2976 \\
\hline
\end{tabular}


Tabela 3 - Ganho de peso médio dos frangos durante o período experimental - Pirassununga - 2007

\begin{tabular}{clccc}
\hline \multirow{2}{*}{ Peso inicial } & & \multicolumn{3}{c}{ Dias } \\
\cline { 3 - 5 } & & $\begin{array}{c}\mathbf{l - 2 1} \\
\mathbf{( k g )}\end{array}$ & $\begin{array}{c}\mathbf{1 - 3 5} \\
\mathbf{( k g )}\end{array}$ & $\begin{array}{c}\mathbf{1 - 4 8} \\
(\mathbf{k g})\end{array}$ \\
\hline Pesada & Rel EM:PB alta & 0,830 & 1,817 & 2,701 \\
& Rel EM:PB baixa & 0,829 & 1,856 & 2,672 \\
\hline Leve & Rel EM:PB alta & 0,785 & 1,753 & 2,569 \\
& Rel EM:PB baixa & 0,777 & 1,777 & 2,627 \\
\hline Probabilidades & CV (\%) & 3,44 & 2,58 & 4,66 \\
& Rel EM:PB & 0,5310 & 0,0334 & 0,8188 \\
& Peso Inicial & $<, 0001$ & 0,0001 & 0,1802 \\
& Interação & 0,6049 & 0,5671 & 0,4958 \\
\hline
\end{tabular}

observando diferença significativa no consumo de ração de 22 a 42 dias de idade. Em contrapartida, Dalanezi et $\mathrm{ll}^{11}$, que estudaram o efeito da idade da matriz sobre o desempenho e rendimento de carcaça, observaram que houve efeito significativo para o consumo de ração, onde o menor consumo foi das aves oriundas de matrizes mais jovens, as quais deram origem à pintos mais leves.

Leandro et a $1^{12}$ observaram diferença significativa $(\mathrm{P}<0,05)$ no ganho de peso obtido para o plano nutricional com maiores níveis energéticos e protéicos, o qual se mostrou superior ao plano com níveis menores, mas não diferiu de planos com níveis intermediários. Ainda discordando, Costa et $\mathrm{al}^{13}$ obtiveram um efeito linear para GP $(\mathrm{P}<0,05)$, sendo que à medida que foi aumentando o nível de proteína da ração, houve um aumento do GP, sem que houvesse efeito sobre o consumo. Por outro lado, Mendes et al. ${ }^{6}$ não observaram efeito significativo $(\mathrm{P}>0,05)$ para o ganho de peso, mas os melhores resultados foram obtidos com os níveis de energia entre 3.020 e 3.140 $\mathrm{kcal} \mathrm{EM/kg}$.

Em relação à conversão alimentar (Tabela 4), houve diferença significativa $(\mathrm{P}<0,05)$ no período de criação de $1-35$ dias. As aves alimentadas com a dieta com baixa relação EM:PB apresentaram pior conversão alimentar quando comparadas com as aves que receberam dietas com relação EM:PB alta, tanto para as aves com maior peso inicial quanto para as aves com menor peso inicial. De maneira independente ao peso inicial, para as aves que receberam o mesmo tipo de dieta, não foi observado efeito significativo $(\mathrm{P}>0,05)$. No período inicial $(1-21$ dias $)$ e no período total $(1-$ 48 dias) de criação, não foi observado efeito significativo $(\mathrm{P}>0,05)$. Leandro et al. ${ }^{12}$ mostraram que a conversão alimentar nas

Tabela 4 - Conversão alimentar dos frangos durante o período experimental - Pirassununga - 2007

\begin{tabular}{|c|c|c|c|c|}
\hline \multirow[b]{2}{*}{ Peso inicial } & & \multicolumn{3}{|c|}{ Dias } \\
\hline & & $1-21$ & $1-35$ & $1-48$ \\
\hline \multirow[t]{2}{*}{ Pesada } & Rel EM:PB alta & 1,09 & $1,38^{\mathrm{aB}}$ & 1,69 \\
\hline & Rel EM:PB baixa & 1,21 & $1,51^{\mathrm{aA}}$ & 1,89 \\
\hline \multirow[t]{3}{*}{ Leve } & Rel EM:PB alta & 1,07 & $1,33^{\mathrm{aB}}$ & 1,70 \\
\hline & Rel EM:PB baixa & 1,26 & $1,54^{\mathrm{aA}}$ & 1,89 \\
\hline & CV (\%) & 7,88 & 6,87 & 6,88 \\
\hline \multirow[t]{3}{*}{ Probabilidades } & Rel EM:PB & $<, 0001$ & $<, 0001$ & 0,0006 \\
\hline & Peso Inicial & 0,4546 & 0,5371 & 0,8817 \\
\hline & Interação & 0,1345 & 0,0970 & 0,8350 \\
\hline
\end{tabular}


fêmeas foi afetada pelos planos nutricionais somente na fase total, em que o plano que continha menor nível de EM e PB apresentou pior CA em relação ao plano com nível médio. Discordando do presente trabalho, Lara et al. ${ }^{14}$, Vieira e Moran $\mathrm{Jr}^{15}$ e Stringhini et al. ${ }^{16}$, observaram que o peso dos pintos só teve influência sobre a conversão alimentar no período de 1 a 21 dias de idade, quando a melhor conversão foi obtida com os da categoria leve $(\mathrm{P}>0,05)$. Por sua vez, Sakomura et al. ${ }^{9}$, observaram que não houve efeito significativo para a conversão alimentar, avaliando o efeito do nível de energia metabolizável da dieta de frangos de corte.

Os resultados de rendimento de carcaça, gordura abdominal e vísceras comestíveis estão apresentados na tabela 5 . Os mesmos mostram que não houve diferença significativa $(\mathrm{P}>0,05)$ para gordura abdominal e vísceras comestíveis. No rendimento de carcaça houve efeito significativo $(\mathrm{P}<0,05)$ onde as aves com maior peso inicial obtiveram um melhor rendimento em relação às aves com peso inicial leve quando receberam, durante todo o período de criação, dietas com relação EM:PB alta. Já entre as aves com peso inicial leve, as que receberam a dieta com relação EM:PB baixa apresentaram um melhor rendimento de carcaça em relação às aves que receberam a dieta com relação $\mathrm{EM}: \mathrm{PB}$ alta $(\mathrm{P}<0,05)$. Entre as aves com maior peso inicial, não houve diferença entre as dietas. Discordando do presente trabalho, Shiroma et al. ${ }^{17}$ estudando o efeito de três programas de alimentação sobre o desempenho de frangos de corte sexados, observaram uma maior porcentagem de gordura abdominal na periferia da moela no programa alimentar em que na fase final as aves receberam uma dieta com o maior valor da relação energia:proteína. Peak et $\mathrm{al}^{18}$, estudando dois planos nutricionais no desempenho e uniformidade de frangos de corte, observaram uma redução no rendimento de carcaça com a diminuição do plano nutricional (menores níveis de PB). Mendes et al. ${ }^{6}$ observaram que os níveis de energia proporcionaram efeito linear $(\mathrm{P}<0,05)$ para gordura abdominal, verificando-se acréscimo da porcentagem de gordura abdominal com o aumento do nível de energia da dieta. Por outro lado, concordando com este trabalho, Leandro et al. ${ }^{12}$ observaram que não houve efeito significativo $(\mathrm{P}>0,05)$ para a porcentagem de gordura abdominal em relação aos diferentes planos nutricionais. Mas, ainda estes autores, observaram que também não houve efeito significativo $(\mathrm{P}>0,05)$ no rendimento de carcaça nos diferentes planos nutricionais, o que discorda deste trabalho.

Os resultados de rendimento dos cortes (asa, coxa+sobrecoxa, peito, cabeça, pé e dorso) estão apresentados na tabela 6 . Em nenhumas das variáveis estudadas houve efeito significativo $(\mathrm{P}>0,05)$. Lara et $\mathrm{al}^{14}$, estudando a influência do peso inicial sobre o desempenho e o rendimento de carcaça e cortes de frango de corte, observaram um maior rendimento de coxa e sobrecoxa das aves da categoria pesada em relação às da categoria média, sendo estas semelhantes às leves $(\mathrm{P}>0,05)$. Dalanezi et al. ${ }^{11}$, estudando

Tabela 5 - Rendimento de carcaça (\%), gordura (\%) e víceras comestíveis (\%) - Pirassununga - 2007

\begin{tabular}{|c|c|c|c|c|c|c|}
\hline \multirow[b]{2}{*}{ Peso inicial } & & \multicolumn{5}{|c|}{ Rendimento } \\
\hline & & $\begin{array}{c}\text { Peso Vivo } \\
\text { (kg) }\end{array}$ & $\begin{array}{c}\text { Peso Carcaça } \\
(\mathrm{kg})\end{array}$ & $\begin{array}{c}\text { Rendimento } \\
(\%)\end{array}$ & $\begin{array}{c}\text { Gordura abd. } \\
(\%)\end{array}$ & $\begin{array}{c}\text { Viceras } \\
(\%)\end{array}$ \\
\hline \multirow[t]{2}{*}{ Pesada } & Rel EM:PB alta & 2,746 & 2,211 & $80,95^{\mathrm{aA}}$ & 2,76 & 3,85 \\
\hline & Rel EM:PB baixa & 2,718 & 2,144 & $80,17^{\mathrm{A}}$ & 2,18 & 3,58 \\
\hline \multirow[t]{3}{*}{ Leve } & Rel EM:PB alta & 2,624 & 2,084 & $79,85^{\mathrm{bB}}$ & 2,55 & 4,05 \\
\hline & Rel EM:PB baixa & 2,666 & 2,157 & $81,09^{\mathrm{aA}}$ & 1,55 & 3,87 \\
\hline & CV (\%) & 4,44 & 4,37 & 1,00 & 26,10 & 12,96 \\
\hline \multirow[t]{3}{*}{ Probabilidades } & Rel E:P & 0,9122 & 0,9488 & 0,5063 & 0,0016 & 0,4059 \\
\hline & Peso Inicial & 0,1789 & 0,2382 & 0,7948 & 0,0522 & 0,3652 \\
\hline & Interação & 0,5809 & 0,1543 & 0,0106 & 0,2966 & 0,8621 \\
\hline
\end{tabular}


Tabela 6 - Rendimento de cortes ( \%) de frangos aos 48 dias de idade - Pirassununga - 2007

\begin{tabular}{|c|c|c|c|c|c|c|c|c|}
\hline \multirow{3}{*}{ Rendimentos } & \multicolumn{5}{|c|}{ Peso Inicial } & \multirow{2}{*}{\multicolumn{3}{|c|}{ Probabilidades }} \\
\hline & \multicolumn{2}{|c|}{ Pesada } & \multicolumn{2}{|r|}{ Leve } & \multirow[b]{2}{*}{$\begin{array}{l}\mathrm{CV} \\
(\%)\end{array}$} & & & \\
\hline & Rel E:P alta & Rel E:P baixa & $\begin{array}{c}\text { Rel E:P } \\
\text { alta }\end{array}$ & Rel E:P baixa & & Rel EM:PB & Peso Inicial & Interação \\
\hline Asa & 9,33 & 9,44 & 9,34 & 9,38 & 2,08 & 0,4703 & 0,8079 & 0,7201 \\
\hline Coxa+Sobre & 28,89 & 28,47 & 29,23 & 29,06 & 1,74 & 0,2259 & 0,0664 & 0,6100 \\
\hline Peito & 35,41 & 35,64 & 34,11 & 34,11 & 3,30 & 0,2887 & 0,1264 & 0,5030 \\
\hline Cabeça & 8,73 & 8,47 & 8,76 & 8,53 & 2,35 & 0,0159 & 0,5965 & 0,8665 \\
\hline Pé & 3,55 & 3,94 & 3,60 & 3,88 & 7,60 & 0,0213 & 0,9689 & 0,6554 \\
\hline Dorso & 13,99 & 14,04 & 14,85 & 14,30 & 5,60 & 0,5494 & 0,1905 & 0,4660 \\
\hline
\end{tabular}

o efeito da idade da matriz sobre o rendimento de carcaça, observaram que não houve efeito significativo sobre o rendimento do dorso ( $>00,05)$. Já o rendimento de pernas foi afetado $(\mathrm{P}<0,05)$ pela idade da matriz apenas aos 21 dias onde aves oriundas de matrizes de 98 semanas apresentaram menor rendimento que aquelas de matrizes com 58 e 68 semanas. Ainda, o rendimento de asa foi afetado $(\mathrm{P}<0,05)$ pela idade da matriz, sendo que as aves oriundas de matrizes com 68 semanas tiveram os piores resultados.

\section{Conclusões}

Com base nos resultados obtidos, pode-se concluir: a ração, com relação EM:PB alta, apresentou melhor CA, independente do peso inicial das aves e as aves com menor peso inicial apresentaram pior rendimento de carcaça quando receberam rações com relação EM:PB alta.

\section{Effect of differents dietary relationship metabolizable energy:crude protein and the initial weight of chicks on the performance and yield of carcass in females broilers}

\section{Abstract}

This study was accomplished to verify the effect of the differents dietary relationship metabolizable energy:crude protein and the initial weight of chicks on the performance and yield of carcass in broilers. There were used 640 female chickens of the commercial ancestry (Cobb). A completely randomized trial was applied, in factorial outline $2 \times 2$, with two levels of chicks' weight (38g and 46g) and two levels of relationship ME:CP (High - 149,8; 174,4 e; 194,4 and, Low - 130,0; 150,0 e; 166,7, for the initial, growth and end ration, respectively), totalizing 4 treatments, each one of them with 4 repetitions of 40 chicks, ranging until 48 days of age. There were evaluated the Feed Intake (FI), Weight Gain (WG), Feed Conversion (FC) and Mortality, during all the experimental period and, performance and chemical composition of carcass in the end of the experimental period. There was no significant difference $(\mathrm{P}>0,05)$ in feed intake and weight gain in the tested treatments. However, there was significant difference $(\mathrm{P}<0,05)$ at the $\mathrm{FC}$, when the broilers were fed with Low Relationship ME:CP ration and showed the worst result, independent of the initial weight, during the 1 to 35 days of age. In the composition of carcass there was significant effect $(\mathrm{P}<0,05)$, where the high initial weight broilers fed with High Relationship ME:CP ration showed better results.

\section{Referências}

1 SILVA, A. B. P.; GARCIA, E. A.; MENDES, A. A. Efeito do sexo sobre o desempenho e uniformidade em lotes de frango de corte: In: CONFERENCIA APINCO DE
Key words: Broiler. Initial weight. Crude protein. Metabolizable energy. Performance. 
f. Dissertação (Mestrado em Produção Animal) Universidade Federal Rural de Pernambuco, Recife, 1997.

3 PENZ, M. Programas de alimentación para pollos. Indústria Avícola, v. 43, n. 10, p. 18-20, 1996.

4 TAVARES, V. A vagem triturada da algarobeira (Prosopis juliflora (SW) D. C.) como ingrediente não ortodoxo de rações para frango de corte. 1993. $163 \mathrm{f}$. Dissertação (Mestrado) - Universidade Federal Rural de Pernambuco, Recife, 1993.

5 HOLSHEIMER, J. P.; VEERCAMP, C. M. Effect of dietary energy, protein and lysine content on performance and yields of two strains of male broiler chicks. Poultry Science, v. 76, n. 5, p. 872-875, 1992.

6 MENDES, A. A.; GARCIA, E. A.; GONZALES, E.; VAROLI, J. C. Efeito da marca comercial e idade de abate sobre o rendimento de carcaça de frangos de corte. Revista da Sociedade Brasileira de Zootecnia, v. 22, n. 3, p. 466-472, 2004.

7 STATISTICAL ANALISYS SYSTEM. SAS user's guide: statistics. Versão 8.2. Cary: SAS Institute, 1999.

8 ROSTAGNO, H. S.; ALBINO, L. F. T.; DONZELE, J. L. Tabelas brasileiras para aves e suínos composição e exigências nutricionais. Viçosa: UFV. 2005. 186 p.

9 SAKOMURA, N. K.; LONGO, F. A.; ROBELLO, C. B.; WATANABE, K.; PELÍCIA, K.; FREITAS, E. R. Efeito do nível de energia metabolizável da dieta no desempenho e metabolismo energético de frango de corte. Revista Brasileira de Zootecnia, v. 33, n. 6, p. 1758-1767, 2004. Suplement, 1.

10 SABINO, H. F. N.; SAKOMURA, N. K.; NEME, R.; FREITAS, E. R. Níveis protéicos na ração de frango de corte na fase de crescimento. Pesquisa Agropecuária Brasileira, v. 39, n. 5, p. 407-412, 2004.

11 DALANEZI, J. A.; MENDES, A. A.; GARCIA, E. A.; GARCIA, R. G.; MOREIRA, J.; PAZ, I. C. L. A. Efeito da idade da matriz sobre o desempenho e rendimento de carcaça de frango de corte. Arquivo Brasileiro de
Medicina Veterinária e Zootecnia, v. 57, n. 2, p. 250260, 2005.

12 LEANDRO, N. S. M.; CAFÉ, M. B.; STRINGHINI, J. H.; MORAES FILHO, R.; MOURA, K. A.; SILVA JÚNIOR, R. P. Plano nutricional com diferentes níveis de proteína bruta e energia metabolizável na ração, para frango de corte. Revista Brasileira de Zootecnia, v. 32, n. 3, p. 620-631, 2003.

13 COSTA, F. G. P.; ROSTAGNO, H. S.; ALBINO, L. F. T.; GOMES, P. C.; TOLEDO, R. S.; VARGAS JÚNIOR, J. G. Níveis dietéticos de proteína bruta para frango de corte de 1 a 21 e 22 a 42 dias de idade. Revista Brasileira de Zootecnia, v. 30, n. 5, p. 1498-1505, 2001.

14 LARA, L. J. C.; BAIÃO, N. C.; CANÇADO, S. V.; TEIXEIRA, J. L.; LOPEZ, C. A. A.; DUARTE, F. D.; MICHALSKY, V. B. Influência do peso inicial sobre o desempenho e o rendimento de carcaça e cortes de frango de corte. Arquivo Brasileiro de Medicina Veterinária e Zootecnia, v. 57, n. 6, p. 799804, 2005.

15 VIEIRA, S. L.; MORAN JR., E. T. Effects of egg, of origin and chick post-hatch nutrition on broiler live performance and meat yields. World 's Poultry Science Journal, v. 55, p. 125-142, 1999.

16 STRINGHINI, J. H.; RESENDE, A.; CAFÉ, M. B.; LEANDRO, N. S. M.; ANDRADE, M. A. Efeito do peso inicial dos pintos e do período da dieta pré-inicial sobre o desempenho de frango de corte. Revista Brasileira de Zootecnia, v. 32, n. 2, p. 353-360, 2003.

17 SHIROMA, N. N.; ZANETTI, M. A.; FARIA D. E. ALBUQUERQUE, R. Efeito de três programas de alimentação sobre o desempenho de frangos de corte sexados. In: REUNIÃO ANUAL DA SOCIEDADE BRASILEIRA DE ZOOTECNIA, 33., 1996, Fortaleza. Anais... 1996. p. 22-24.

18 PEAK, S. D.; WALSH, T. J.; BENTON, C. E; BRAKE, $J$. Effects of two planes of nutrition on performance and uniformity of four strains of broiler chicks. Journal of Applied Poultry Research, v. 9, n. 2, p. 185-194, 2000. 